\title{
VALIDAÇÃO DE MÉTODOS PARA DETERMINAÇÃO DE FLUOXETINA EM CÁPSULAS
}

Marlene Maria Fregonezi-Nery*, Marcela Maria Baracat, Rubia Casagrande, Hodnei Takashi Machado, Bruna Miglioranza e Elisabeth Aparecida dos Santos Gianotto

Departamento de Ciências Farmacêuticas, Centro de Ciências da Saúde, Universidade Estadual de Londrina, Campus Universitário, CP 6001, 86051-990 Londrina - PR, Brasil

José Carlos Dalmas

Departamento de Estatística, Centro de Ciências Exatas, Universidade Estadual de Londrina, Campus Universitário, CP 6001, 86051-990 Londrina - PR, Brasil

Recebido em 11/9/07; aceito em 22/4/08; publicado na web 17/9/08

\begin{abstract}
VALIDATION OF METHODS FOR DETERMINATION OF FLUOXETINE CAPSULES. A UV spectrophotometric method was developed and validated and a chromatographic method was adapted from the American Pharmacopeia for the analysis of Fluoxetine Hydrochloride capsules. Ethanol was used as solvent for the spectrophotometric method, with detection and determination at $276 \mathrm{~nm}$. The separation for the chromatographic method was carried out using the reversed-phase column LC-8, triethylamine buffer, stabilizer free tetrahydrofuran and methanol (5:3.5:1.5), $\mathrm{pH} 6.0$ as mobile phase and detection at $227 \mathrm{~nm}$. The results obtained for both methods showed to be accurate, precise, robust and linear over the concentration range $100.00-300.00 \mu \mathrm{g} / \mathrm{mL}$ and $40.00-80.00 \mu \mathrm{g} / \mathrm{mL}$ of fluoxetine hydrochloride for the spectrophotometric and chromatographic methods, respectively. The accuracy of the methods was evaluated by a recovery test and showed results between 98.89 and $101.10 \%$.
\end{abstract}

Keywords: fluoxetine; UV spectrophotometry; high performance liquid chromatography.

\section{INTRODUÇÃO}

A Organização Mundial de Saúde (OMS) prevê que nos próximos 20 anos, a depressão sairá do quarto para o segundo lugar na lista de doenças dispendiosas e fatais e deverá perder apenas para as enfermidades do coração. Os últimos dados revelaram que hoje a depressão atinge $15 \%$ da população, em 70 a $80 \%$ dos casos é uma doença crônica recidivante, ${ }^{1}$ representando uma parcela significativa de despesas com a saúde. Ainda, o mais importante é o fato de que aproximadamente $15 \%$ das pessoas que sofrem de depressão cometem suicídio, principalmente se não forem tratadas de modo correto. ${ }^{2}$

O cloridrato de fluoxetina ou cloridrato de N-metil- $\gamma$-[4(trifluorometil)fenoxi]-benzenopropanamina (Figura 1) é um inibidor seletivo da recaptação de serotonina, amplamente utilizado no tratamento da depressão por ser mais aceitável em termos de tolerância e toxicidade. É mundialmente conhecido como Prozac ${ }^{\circledR}$ e encontra-se disponível no mercado na forma de cápsulas, comprimidos, comprimidos revestidos e solução oral.

Vários trabalhos apresentaram a cromatografia líquida de alta eficiência (CLAE) para determinação de fluoxetina em medicamentos. O método oficial descrito pela Farmacopéia Americana $29^{\text {th }}$ ed. ${ }^{3}$ e Farmacopéia Brasileira $4^{\mathrm{a}}$ ed. ${ }^{4}$ utiliza a CLAE, empregando coluna C-8 (250 mm x 4,6 $\mathrm{mm}$ ), fase móvel constituída de tampão trietilamina $\mathrm{pH}$ 6,0: tetraidrofu-

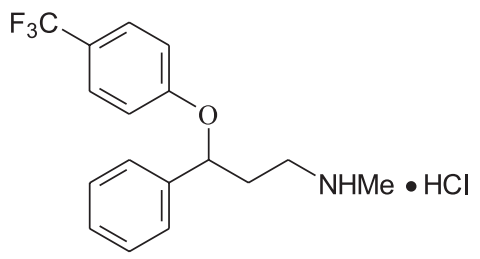

Figura 1. Cloridrato de fluoxetina

*e-mail: nery@uel.br rano sem estabilizante: metanol (6:3:1), fluxo de $1 \mathrm{~mL} / \mathrm{min}$ e detecção no ultravioleta a $227 \mathrm{~nm}$. Outras condições cromatográficas descritas foram: coluna C-8, fase móvel tampão perclorato de tetrametilamônio: acetonitrila com detecção no UV e fluorimétrica; 5 fase móvel constituída de água $\mathrm{pH} 3,5$ : acetonitrila (65:35); ${ }^{6}$ fosfato de potássio $\mathrm{pH} 3,0$ e acetonitrila (65:35) como fase móvel e detecção em $232 \mathrm{~nm} ;{ }^{7}$ acetonitrila: tampão de trietilamina (48:52), detecção no UV a $226 \mathrm{~nm}^{8}$ e fase móvel constituída de acetonitrila e tampão fosfato $\mathrm{pH} 3,0$ (1:1). ${ }^{9}$

Vários autores utilizam a espectrofotometria na região do visível com formação de complexos coloridos reagindo a fluoxetina com: alaranjado de metila em $\mathrm{pH} 4,0$ e azul de timol em $\mathrm{pH} 8,0,{ }^{10}$ cloranil e com 2,3-dicloro-5,6-dicianoquinona, ${ }^{11}$ eriocromo $\mathrm{R},{ }^{12}$ violeta de pirocatecol em meio aquoso ${ }^{13}$ e azul de bromotimol, verde de bromocresol ou azul de bromofenol em tampão ácido. ${ }^{14}$

Outros métodos alternativos foram propostos para determinação de fluoxetina em cápsulas, tais como espectrofotometria e cromatografia gasosa, ${ }^{15}$ espectrofluorimetria, ${ }^{16}$ espectrofluorimetria e eletroforese capilar $^{17}$ e espectrofotometria no ultravioleta a $225 \mathrm{~nm}^{18}$ e a $227 \mathrm{~nm}^{4}$

O objetivo deste trabalho foi desenvolver e validar um método espectrofotométrico e um outro cromatográfico para análise rotineira de controle de qualidade de cápsulas de cloridrato de fluoxetina, que possam ser empregados tanto em indústria farmacêutica como em farmácias de manipulação.

\section{PARTE EXPERIMENTAL}

\section{Materiais e reagentes}

Amostras comerciais de cápsulas de cloridrato de fluoxetina 20 mg (amostra 1) e a matéria-prima (amostra 2) foram gentilmente cedidas pela Biossintética Farmacêutica Ltda., São Paulo. Amostras de cápsulas de cloridrato de fluoxetina $20 \mathrm{mg}$ manipuladas (amostras 3 , 4, 5 e 6) foram adquiridas nas farmácias de manipulação da cidade de Londrina - PR. Empregou-se como substância química de referência 
o cloridrato de fluoxetina USP (lote: F2C132).

Os excipientes estudados no teste de seletividade foram os comumente empregados na formulação de cápsulas: celulose microcristalina, manitol, amido de milho, dióxido de silício e estearato de magnésio, todos de grau farmacêutico.

Todos os reagentes químicos utilizados foram de grau analítico. Etanol absoluto (J. B. Backer, Nuclear e Synt), tetra-hidrofurano sem estabilizante grau cromatográfico (J. T. Backer), metanol grau cromatográfico (J. T. Backer), trietilamina (Sigma-Aldrich), ácido fosfórico (Qhemis) e ácido clorídrico (Merck). A água empregada no preparo das soluções foi purificada pelo sistema Milli- ${ }^{\circledR}$.

\section{Equipamentos e condições analíticas}

Foi utilizado um espectrofotômetro UV-Vis (Shimadzu, modelo160-A) de duplo feixe, detector de 190 a 1100 nm e cubetas de quartzo de $1 \mathrm{~cm}$. Para o método espectrofotométrico proposto (método A) foi utilizado etanol absoluto como solvente e para o método oficial da Farmacopéia Brasileira (método B), solução de $\mathrm{HCl}$ 0,1 $\mathrm{mol} / \mathrm{L}$. O aparelho foi calibrado com os respectivos solventes e a leitura das absorvâncias foi realizada a $276 \mathrm{~nm}$ para o método A e a 227 nm para o método B. O método C, cromatográfico, foi adaptado do método oficial da Farmacopéia Americana. Foi utilizado cromatógrafo marca Varian, modelo ProStar 230 com comprimento de onda variável, detector de arranjo de diodos (modelo ProStar 330) e injetor automático (modelo ProStar 410). Para a separação cromatográfica foi utilizada coluna analítica C8 - ChromSpher $(250 \mathrm{~mm}$ x 4,6 mm, $5 \mu \mathrm{m}$ ) mantida a $30{ }^{\circ} \mathrm{C}$ durante a análise. A fase móvel foi solução tampão de trietilamina com pH 6,00 $\pm 0,05$ ajustado com ácido fosfórico, tetra-hidrofurano sem estabilizante e metanol (5,0: 3,5: 1,5; v/v) com vazão de $1 \mathrm{~mL} / \mathrm{min}$ e detecção a $227 \mathrm{~nm}$. Todas eluições foram em condições isocráticas.

\section{Validação dos métodos}

Os métodos propostos (A e C) foram avaliados e validados conforme Resolução RE $899^{19}$ e International Conference on Harmonization $(\mathrm{ICH}) .{ }^{20}$ Os métodos foram comparados estatisticamente com o método espectrofotométrico da Farmacopéia Brasileira $4^{\mathrm{a}}$ ed. ${ }^{4}$

\section{Especificidade}

Método A: preparou-se solução padrão de cloridrato de fluoxetina $200 \mu \mathrm{g} / \mathrm{mL}$ em etanol absoluto e soluções placebo de cada excipiente preparadas na concentração correspondente a $100 \%$ da quantidade declarada de analito na formulação. Traçou-se o espectro de cada solução na faixa de 220 a $350 \mathrm{~nm}$ e observou-se a presença de sinais na faixa de leitura do analito.

Método C: foi preparada uma solução padrão de cloridrato de fluoxetina $60,00 \mu \mathrm{g} / \mathrm{mL}$ em fase móvel e soluções placebo de cada excipiente na concentração correspondente a $100 \%$ da quantidade declarada de analito na formulação. As soluções padrão e placebos foram injetadas no cromatográfo e avaliada a presença de picos na região do tempo de retenção do analito.

\section{Linearidade}

Foram preparadas soluções em triplicata nas concentrações de 100,$00 ; 150,00 ; 200,00 ; 250,00$ e $300,00 \mu \mathrm{g} / \mathrm{mL}$ de cloridrato de fluoxetina (substância química de referência) em etanol absoluto; de 5,$00 ; 10,00 ; 15,00 ; 20,00$ e $25,00 \mu \mathrm{g} / \mathrm{mL}$ em $\mathrm{HCl} 0,1 \mathrm{~mol} / \mathrm{L}$ e de $40,00,50,00,60,00,70,00$, e $80,00 \mu \mathrm{g} / \mathrm{mL}$ em fase móvel para os métodos A, B e C, respectivamente. A equação da reta foi obtida pelo método dos mínimos quadrados e calculou-se o coeficiente de correlação de Pearson.

\section{Precisão}

A repetibilidade e a precisão intermediária foram determinadas partindo-se de 6 tomadas de ensaio de $12,50 \mathrm{mg}$ de cloridrato de fluoxetina (amostra 2), obtendo-se soluções na concentração de $250,00 \mu \mathrm{g} / \mathrm{mL}$ para o método $\mathrm{A}, 15,00 \mu \mathrm{g} / \mathrm{mL}$ para o método B e $50,00 \mu \mathrm{g} / \mathrm{mL}$ para o método C. As soluções foram determinadas em triplicata. A precisão intermediária foi avaliada no mesmo laboratório, utilizando o mesmo equipamento em dias diferentes e com analistas diferentes. A partir dos resultados obtidos foram calculados o desvio padrão (DP) e coeficiente de variação $(\mathrm{CV})$.

\section{Exatidão}

A exatidão, expressa em porcentagem, foi avaliada a partir da adição e recuperação de quantidades conhecidas de cloridrato de fluoxetina padrão em amostras comerciais. Para o método A foram preparadas soluções em triplicata contendo mistura de solução amos-

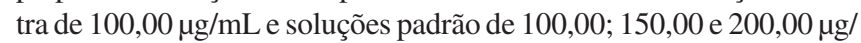
$\mathrm{mL}$ de cloridrato de fluoxetina. Para o método $\mathrm{B}$, mistura de solução amostra de 5,00 $\mu \mathrm{g} / \mathrm{mL}$ e solução padrão de 5,00; 10,00 e 15,00 $\mu \mathrm{g} /$ $\mathrm{mL}$ e para o método $\mathrm{C}$, mistura de solução amostra de $30,00 \mu \mathrm{g} / \mathrm{mL}$ e soluções padrões de 30,00; 40,00 e 50,00 $\mu \mathrm{g} / \mathrm{mL}$. As quantidades recuperadas de cloridrato de fluoxetina padrão adicionadas foram obtidas a partir da curva de calibração. A recuperação de 98,00 a $102,00 \%$ é recomendada para exatidão do método.

\section{Robustez}

O estudo foi efetuado utilizando três fabricantes de etanol absoluto para o método A e variação do $\mathrm{pH}$ da fase móvel $(5,00 ; 5,50 ; 5,80$; 6,$00 ; 6,20 ; 6,50$ e 7,00) para o método C. As análises foram realizadas em triplicata. As concentrações de cloridrato de fluoxetina, expressas em $\mu \mathrm{g} / \mathrm{mL}$, foram obtidas a partir da curva de calibração.

\section{Limites de detecção (LD) e de quantificação (LQ)}

O LD e o LQ da fluoxetina para os métodos propostos foram determinados a partir das respectivas curvas de calibração padrão e foram calculados como $3 x \sigma / \mathrm{S}$ e $10 x \sigma / \mathrm{S}$, respectivamente, onde $\sigma$ é o desvio padrão do intercepto com o eixo Y de 3 curvas de calibração e S é a inclinação da curva padrão.

\section{Análise estatística para comparação dos métodos}

Os resultados obtidos pela aplicação dos três métodos foram comparados estatisticamente empregando a análise de variância (ANOVA fator único) ao nível de 95\% de confiança. Para avaliação estatística da robustez empregou-se ANOVA fator único e o teste de Tukey.

\section{Aplicação do método em cápsulas comerciais e manipuladas}

O teor de fluoxetina no produto comercial (amostra 1) e cápsulas manipuladas (amostra 3, 4, 5 e 6) foi determinado utilizando o método espectrofotométrico proposto. Foram pesadas 10 unidades e partindo de um peso médio dilui-se em etanol absoluto obtendo-se solução contendo 268,32 $\mu \mathrm{g} / \mathrm{mL}$ de fluoxetina. As análises foram realizadas em triplicata e as absorvâncias foram determinadas em espectrofotômetro a $276 \mathrm{~nm}$ contra etanol absoluto como branco. As concentrações expressas em $\mu \mathrm{g} / \mathrm{mL}$ foram obtidas a partir da curva de calibração. 
Tabela 1. Resultados da análise de regressão linear dos métodos A, B e C da curva de calibração do cloridrato de fluoxetina

\begin{tabular}{lccc}
\hline Parâmetros estatísticos & Método A & Método B & Método C \\
\hline Equação de regressão & $\mathrm{y}=-0,0016+0,00135 \mathrm{X}$ & $\mathrm{y}=0,0053+0,04062 \mathrm{X}$ & $\mathrm{y}=656032,2+198556 \mathrm{X}$ \\
Coeficiente de correlação & 0,9999 & 0,9999 & 0,9988 \\
Erro padrão da inclinação & 0,000026 & 0,000132 & 5625,9 \\
Erro padrão da interseção & 0,006843 & 0,002192 & 346803,9 \\
\hline
\end{tabular}

Método A: UV (proposto) Método B (Farmacopéia Brasileira) Método C: CLAE (proposto)

\section{RESULTADOS E DISCUSSÃO}

A Figura 2 apresenta o espectro de absorção do cloridrato de fluoxetina em etanol absoluto e pode-se observar o pico máximo de absorção a $276 \mathrm{~nm}$.

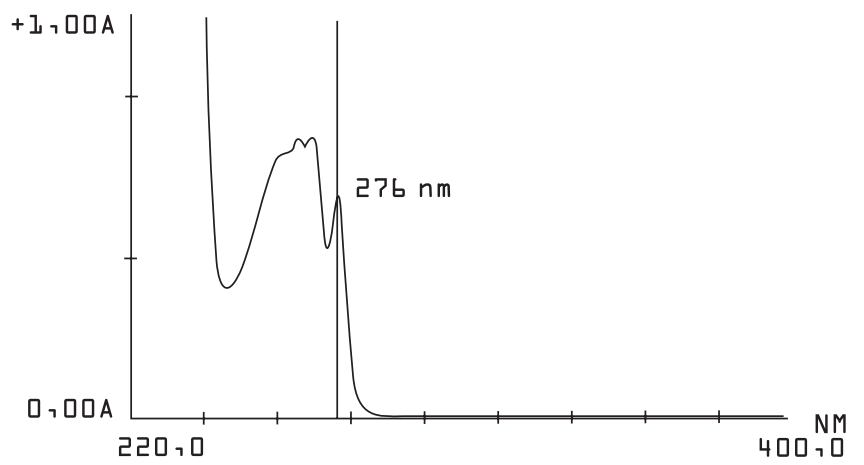

Figura 2. Espectro de absorção do cloridrato de fluoxetina $250 \mu \mathrm{g} / \mathrm{mL} \mathrm{em}$ etanol absoluto

O método cromatográfico descrito na monografia da Farmacopéia Americana, para determinação de teor de cápsulas de cloridrato de fluoxetina utilizando fase móvel constituída de tampão trietilamina: tetra-hidrofurano: metanol na proporção de 6:3:1, apresentou tempo de retenção de 11,3 min. Alterações nas proporções dos solventes utilizados de 5:3,5:1,5 proporcionaram a redução do tempo de retenção para 6,3 min, favorecendo análise rápida para ser aplicada em rotina.

Os resultados da especificidade comprovam que os excipientes estudados não interferem na análise de cápsulas de cloridrato de fluoxetina quando foram utilizados os métodos propostos (A e C), nas condições experimentais.

As curvas de calibração para os métodos A e B foram obtidas a partir da relação absorvância x concentração e para o método $\mathrm{C}$ a partir da relação área do pico x concentração. A curva padrão dos métodos A, B e C apresentou linearidade dentro da faixa de concentração de 100,00 a $300,00 \mu \mathrm{g} / \mathrm{mL}$ com coeficiente de correlação de 0,9999 , de 5,00 a $25,00 \mu \mathrm{g} / \mathrm{mL}$ com coeficiente de correlação de 0,9999 e de 40,00 a $80,00 \mu \mathrm{g} / \mathrm{mL}$ com coeficiente de correlação de 0,9988 , respectivamente (Tabela 1 ).

Os resultados apresentados na Tabela 2 indicam que os métodos têm boa repetibilidade, com desvio padrão relativo de 1,00; 2,03 e $0,24 \%$, respectivamente, para os métodos A, B e C, inferiores a $5 \%$, valor máximo recomendado pela legislação vigente. ${ }^{19}$

A Tabela 3 apresenta os resultados da precisão intermediária efetuado por diferentes analistas e dias diferentes e demonstram que os métodos apresentam boa precisão.

Os resultados da exatidão dos métodos $\mathrm{A}, \mathrm{B}$ e $\mathrm{C}$ estão na faixa de 98,89 a $101,11 \%, 100,07$ a $100,60 \%$ e 99,00 a $100,75 \%$, respectivamente, e confirmam que os métodos apresentaram uma ótima exatidão (Tabela 4).
Tabela 2. Resultados do ensaio de repetibilidade de solução de cloridrato de fluoxetina matéria-prima (amostra 2) na concentração de $250,00,15,00$ e $50,00 \mu \mathrm{g} / \mathrm{mL}$ para os métodos A, B e C, respectivamente $(\mathrm{n}=6)$

\begin{tabular}{lccc}
\hline & Método A & Método B & Método C \\
\hline Média $(\mu \mathrm{g} / \mathrm{mL})$ & 254,27 & 13,82 & 52,66 \\
$\mathrm{DP}^{*}$ & 2,53 & 0,28 & 0,13 \\
$\mathrm{CV}^{* *}(\%)$ & 1,00 & 2,03 & 0,25 \\
\hline
\end{tabular}

Método A: UV (proposto) Método B (Farmacopéia Brasileira) Método C: CLAE (proposto). * Desvio padrão. **Coeficiente de variação

Tabela 3. Resultados da precisão intermediária empregando cloridrato de fluoxetina matéria-prima (amostra 2) na concentração de 250,00; 15,00 e $50,00 \mu \mathrm{g} / \mathrm{mL}$ para os métodos A, B e C, respectivamente

\begin{tabular}{|c|c|c|c|c|c|}
\hline Analistas & Dia & Método & $\begin{array}{l}\text { Concentração } \\
(\mu \mathrm{g} / \mathrm{mL}) \mathrm{n}=6\end{array}$ & $\mathrm{DP}^{*}$ & $\mathrm{CV}^{* *}(\%)$ \\
\hline \multirow{6}{*}{1} & \multirow{3}{*}{1} & A & 254,27 & 2,53 & 1,00 \\
\hline & & B & 13,82 & 0,28 & 2,03 \\
\hline & & $\mathrm{C}$ & 52,66 & 0,13 & 0,25 \\
\hline & \multirow{3}{*}{2} & A & 253,65 & 4,11 & 1,62 \\
\hline & & B & 14,58 & 0,40 & 2,74 \\
\hline & & $\mathrm{C}$ & 52,24 & 0,35 & 0,67 \\
\hline \multirow{6}{*}{2} & \multirow{3}{*}{1} & A & 252,72 & 1,90 & 0,75 \\
\hline & & B & 13,34 & 0,36 & 2,70 \\
\hline & & $\mathrm{C}$ & 49,78 & 0,30 & 0,60 \\
\hline & \multirow{3}{*}{2} & A & 257,71 & 5,36 & 2,08 \\
\hline & & B & 13,37 & 0,32 & 2,39 \\
\hline & & $\mathrm{C}$ & 50,15 & 0,25 & 0,50 \\
\hline
\end{tabular}

Método A: UV (proposto), Método B (Farmacopéia Brasileira), Método C: CLAE (proposto). * Desvio padrão. **Coeficiente de variação

Tabela 4. Resultados da porcentagem de recuperação de padrão de cloridrato de fluoxetina adicionado à amostra 1 para os métodos $\mathrm{A}, \mathrm{B}$ e C

\begin{tabular}{lccc}
\hline Método & $\begin{array}{c}\text { Quantidade adi- } \\
\text { cionada }(\mu \mathrm{g} / \mathrm{mL})\end{array}$ & $\begin{array}{c}\text { Quantidade } \\
\text { recuperada } \\
(\mu \mathrm{g} / \mathrm{mL})(\mathrm{n}=3)\end{array}$ & $\%$ recuperada $( \pm \mathrm{DP} *)$ \\
\hline A & 100,00 & 100,12 & $100,12( \pm 0,03)$ \\
& 150,00 & 148,34 & $98,89( \pm 0,02)$ \\
& 200,00 & 202,21 & $101,11( \pm 0,04)$ \\
B & 5,00 & 5,03 & $100,60( \pm 0,05)$ \\
& 10,00 & 10,03 & $100,30( \pm 0,07)$ \\
& 15,00 & 15,01 & $100,07( \pm 0,01)$ \\
C & 30,00 & 29,70 & $99,00( \pm 0,37)$ \\
& 40,00 & 40,30 & $100,75( \pm 0,80)$ \\
& 50,00 & 50,10 & $100,20( \pm 0,49)$ \\
\hline
\end{tabular}

Método A: UV (proposto), Método B (Farmacopéia Brasileira), Método C: CLAE (proposto). * Desvio padrão 
Tabela 5. Resultados da avaliação da robustez do método A utilizando solução de cloridrato de fluoxetina $280,00 \mu \mathrm{g} / \mathrm{mL}$ (amostra 1) variando-se o fornecedor de etanol absoluto

\begin{tabular}{lcc}
\hline Fornecedor de etanol absoluto & Média $( \pm \mathrm{DP} *)$ & $\mathrm{CV}^{* *}(\%)$ \\
\hline A & $279,86( \pm 2,71)$ & 0,97 \\
B & $276,65( \pm 3,25)$ & 1,17 \\
C & $276,34( \pm 1,03)$ & 0,37 \\
\hline
\end{tabular}

* Desvio padrão. **Coeficiente de variação
Tabela 6. Avaliação da robustez do método C utilizando solução de cloridrato de fluoxetina $60 \mu \mathrm{g} / \mathrm{mL}$ (amostra 1) variando o $\mathrm{pH}$ da fase móvel

\begin{tabular}{lcc}
\hline Valor de $\mathrm{pH}$ & Média $( \pm \mathrm{DP} *)$ & $\mathrm{CV}^{* *}(\%)$ \\
\hline 5,00 & $61,35( \pm 0,45)$ & 0,73 \\
5,50 & $60,23( \pm 0,71)$ & 1,18 \\
5,80 & $60,64( \pm 0,46)$ & 0,76 \\
6,00 & $60,56( \pm 0,52)$ & 0,86 \\
6,20 & $60,48( \pm 0,68)$ & 1,12 \\
6,50 & $61,36( \pm 0,48)$ & 0,78 \\
7,00 & $62,42( \pm 0,34)$ & 0,54 \\
\hline
\end{tabular}

* Desvio padrão. **Coeficiente de variação

Tabela 7. Resultados estatísticos da robustez dos métodos A e C utilizando ANOVA fator único

\begin{tabular}{|c|c|c|c|c|c|c|c|}
\hline Método & Fonte da variação & Graus de Liberdade & Soma dos Quadrados & Quadrado médio & $\mathrm{F}^{\text {业 }}$ & $\mathrm{F}_{\text {crítico }}$ & $\mathrm{p}^{*}$ \\
\hline \multirow{3}{*}{ A } & Fornecedores & 2 & 22,83 & 11,41 & 1,80 & 5,14 & 0,243 \\
\hline & Resíduo & 6 & 37,95 & 6,33 & & & \\
\hline & Total & 8 & 60,78 & & & & \\
\hline \multirow{3}{*}{$\mathrm{C}$} & $\mathrm{pH}$ & 6 & 10,36 & 1,73 & $6,1^{* * * *}$ & 2,84 & $0,003^{* * * *}$ \\
\hline & Resíduo & 14 & 3,97 & 0,28 & & & \\
\hline & Total & 20 & 14,33 & & & & \\
\hline
\end{tabular}

*nível de significância $\mathrm{p}=5 \%$. ${ }^{* *} \mathrm{~F}$ de Snedocor. ${ }^{* * *}$ valor significativo

Tabela 8. Resultado estatístico da comparação dos métodos A, B e C para determinação de cloridrato de fluoxetina cápsulas (amostra 1), empregando ANOVA fator único

\begin{tabular}{|c|c|c|c|c|c|c|}
\hline Método & $\mathrm{n}$ & Soma & Média & Variância & & \\
\hline A & 6 & 596,51 & 99,42 & 1,77922 & & \\
\hline B & 6 & 597,63 & 99,61 & 0,25163 & & \\
\hline $\mathrm{C}$ & 6 & 601,15 & 100,19 & 1,44966 & & \\
\hline Fonte da variação & Gl & SQ & MQ & $\mathrm{F}$ & valor-P & F crítico \\
\hline Métodos & 2 & 1,954133 & 0,977067 & 0,842177 & 0,450157 & 3,682320 \\
\hline Resíduos & 15 & 17,40252 & 1,160168 & & & \\
\hline Total & 17 & 19,35665 & & & & \\
\hline
\end{tabular}

GL: graus de liberdade; SQ: Soma dos Quadrados; MQ: Quadrado médio, F de Snedocor; P: nível de significância $\mathrm{p}=5 \%$.

Tabela 9. Resultados de teor de cápsulas de cloridrato de fluoxetina $20 \mathrm{mg}$ do produto comercial (amostra 1) e manipulado (amostras 3, 4, 5 e 6) utilizando o método espectrofotométrico no UV a $276 \mathrm{~nm}$ na concentração de $268,32 \mu \mathrm{g} / \mathrm{mL}$

\begin{tabular}{lc}
\hline Amostra & Teor* $(\%)$ \\
\hline 1 & 100,80 \\
3 & 98,93 \\
4 & 100,43 \\
5 & 98,19 \\
6 & 99,06 \\
\hline
\end{tabular}

* Média de 3 repetições

Os resultados da avaliação da robustez dos métodos A e C estão apresentados nas Tabelas 5 e 6, respectivamente. Os resultados do estudo estatístico da robustez para os métodos A e C (Tabela 7), realizado através da ANOVA fator único ao nível de $95 \%$ de confiança, mostraram que não há diferença significativa $(\mathrm{p}=0,243)$ entre os três fornecedores de etanol absoluto estudados para o método es- pectrofotométrico, porém, para o método cromatográfico, o estudo do $\mathrm{pH}$ da fase móvel demonstrou que há diferença estatisticamente significativa $(p=0,003)$. Aplicando o teste de Tukey verificou-se que a fase móvel com pH 7,00 apresenta diferença estatística em relação aos outros $\mathrm{pH}$ estudados, sendo o método robusto com fase móvel de pH 5,00; 5,50; 5,80; 6,00; 6,20 e 6,50.

Para o método A o LD e LQ encontrados foram de 4,67 e 14,16 $\mu \mathrm{g} / \mathrm{mL}$, respectivamente, e para o método C o LD foi 3,29 e o LQ $9,96 \mu \mathrm{g} / \mathrm{mL}$.

A análise estatística para comparação dos métodos A e C propostos com o método oficial da Farmacopéia Brasileira (método B), empregando ANOVA fator único, não apresentou diferença estatisticamente significativa ( $\mathrm{p}=0,45)$ (Tabela 8). Assim, os métodos A e C podem ser adequadamente empregados na quantificação de cloridrato de fluoxetina em cápsulas comerciais e manipuladas.

A especificação de teor de fluoxetina em cápsulas segundo os compêndios oficiais ${ }^{3,4}$ é de 90,00 a 110,00\% do valor declarado. Os resultados do doseamento (Tabela 9) apresentam valores dentro dos limites especificados, tanto para o produto comercial como para as cápsulas manipuladas. 


\section{CONCLUSÃO}

Os métodos analíticos propostos para determinação de cloridrato de fluoxetina em cápsulas por CLAE e por UV são específicos, exatos, robustos e lineares na faixa de 40,00 a $80,00 \mu \mathrm{g} / \mathrm{mL}$ e 100,00 a $300,00 \mu \mathrm{g} / \mathrm{mL}$, respectivamente. A aplicação da ANOVA fator único indica que os métodos propostos são equivalentes estatisticamente ao método oficial. O método espectrofotométrico, entretanto, quando comparado ao método cromatográfico é uma alternativa econômica e de fácil execução, podendo ser utilizado em análise rotineira de controle de qualidade de cápsulas de fluoxetina.

\section{AGRADECIMENTOS}

Ao auxílio financeiro do CNPq, ao Programa de Iniciação Científica da Universidade Estadual de Londrina e ao Dr. F. T. de Moura pela prescrição de cápsulas de fluoxetina.

\section{REFERENCIAS}

1. Thase, M. E.; J. Clin. Psychiatry 1999, 60, 3.

2. Kasper, S.; Int. Clin. Psychopharmacol. 1999, 14, 27.

3. UNITED States Pharmacopeia, $29^{\text {th }}$ ed., United pharmacopeial convention: Rockville, 2006.

4. Farmacopéia Brasileira 4a ed., Atheneu: São Paulo, 2005.

5. Raggi, M. A.; Bugamelli, F.; Casamenti, G.; Mandrioli, R.; De Ronchi, D.; Volterra, V.; J Pham. Biomed. Anal. 1998, 18, 699.

6. Bueno, F.; Bergold, A M.; Fröehlich, P. E.; Boll. Chim. Farm. 2000, 139, 256.
7. Bertholdi, K. G.; Bueno, F.; Bergold, A. M.; Acta Farm. Bonaerense 2001, 20, 209.

8. EL-Dawy, M. A.; Mabrouk, M. M.; El-Barbary, F. A.; J. Pharm. Biomed. Anal. 2002, 30, 561

9. Prado, J. N.; Pissatto, S.; Morais, E. C.; Foppa, T.; Murakami, F. S.; Silva, M. A. S.; Acta Pharm. Bonaerense 2006, 3, 436.

10. Prabhakar, A. H.; Patel, V. B.; Giridhar, R.; J Pham. Biomed. Anal. 1999, 20, 427.

11. Bebawy, L. I.; El-Kousy, N.; Suddik, J. K.; Shokry, M.; J Pharm. Biomed. Anal. 1999, 21, 133.

12. Starczewska, B.; J. Trace Microprobe Technol. 2001, 19, 19.

13. Starczewska, B.; Jasinska, A.; Bialous, B.; Pharmazie 2003, 58, 245.

14. Onal, A.; Kepekci, S. E.; Cetin, M.; Erturk, S.; J. AOAC Int. 2006, 89, 966.

15. Berzas, N. J. J.; Villasenor, L. M. J.; Contento, S. A. M.; Aguas Nuevo, E.; J. Chromatogr. Sci. 2000, 38, 200.

16. Berzas, N. J. J.; Alañón, A.; Lázaro, J. A.; Talanta 2002, 58, 301.

17. Mandrioli, R.; Pucci, V.; Visini, D.; Varani, G.; Raggi, M. A.; J. Pharm. Biomed. Anal. 2002, 29, 1127.

18. Sujatha, K.; Chitra, K.; Kumar, P. A.; Kiranbabu, K.; Vasantha, J.; Indian J. Pharm. Sci. 2004, 66, 457.

19. Brasil. Resolução RE No 899, de 29 de Maio de 2003. Agência Nacional de Vigilância Sanitária. Poder Executivo, Brasília, D.O.U. 02 jun. 2003.

20. ICH, International Conference on Harmonization of Technical Requirements for Registration on Pharmaceuticals for Human Use Q2A, "Text on Validation of Analytical Procedures" Genebra 1995. 